\title{
Overland transport of recreational boats as a spreading vector of zebra mussel Dreissena polymorpha
}

\author{
Lukas De Ventura • Nora Weissert • \\ Robert Tobias $\cdot$ Kirstin Kopp $\cdot$ Jukka Jokela
}

Received: 2 December 2014 / Accepted: 29 February 2016/Published online: 10 March 2016

(C) Springer International Publishing Switzerland 2016

\begin{abstract}
In aquatic ecosystems invasive species are among the most important threats to biodiversity worldwide. Understanding the dispersal mechanisms of aquatic invaders is very important for protection and management of vulnerable water bodies. Here we ask how recreational boats that are transported overland could contribute to the dispersal of invasive zebra mussels among lakes in Switzerland. Using a questionnaire sent to registered boat owners, we surveyed properties of transported boats and collected
\end{abstract}

Electronic supplementary material The online version of this article (doi:10.1007/s10530-016-1094-5) contains supplementary material, which is available to authorized users.

L. De Ventura $(\bowtie) \cdot$ N. Weissert · K. Kopp · J. Jokela

Aquatic Ecology, Swiss Federal Institute for Environmental Sciences and Technology (EAWAG), Überlandstrasse 133, 8600 Dübendorf, Switzerland

e-mail: lukas.deventura@eawag.ch

L. De Ventura · N. Weissert · K. Kopp · J. Jokela Institute for Integrative Biology (IBZ), Federal Institute of Technology Zurich (ETHZ), Ueberlandstrasse 133, 8600 Dübendorf, Switzerland

R. Tobias

Environmental Social Sciences, Swiss Federal Institute for Environmental Sciences and Technology (EAWAG), Überlandstrasse 133, 8600 Dübendorf, Switzerland

R. Tobias

Department of Psychology, Social Psychology, University of Zurich, Binzmuehlestrasse 14/15, 8050 Zurich,

Switzerland information on self-reported mussel fouling and transport activities of boat owners. We also sampled boat hulls at launching ramps and harbors for biofouling invertebrates. Boats that were kept seasonally or yearround in water were found to have high vector potential with mussel fouling rates of more than $40 \%$. However, only about $6 \%$ of boats belonging to these groups were transported overland to other water bodies. Considering that approximately 100,000 recreational boats are registered in Switzerland, we estimated that every year around 1400 boats fouled with mussels are transported overland. Such boats pose a high risk of distributing zebra mussels between water bodies. Our results suggest that there is a considerable risk that recreational boats may spread new fouling species to all navigable water bodies within the study area. We speculate that one such species could be the quagga mussel, which has not yet invaded lakes in Switzerland. On a more positive note, our study has identified the group of high-risk boats so that possible control measures would only affect a relatively small number of boat owners.

Keywords Recreational boating - Invasive species · Distribution vectors - Dreissena polymorpha . Fragmented river networks $\cdot$ Small craft boats

\section{Introduction}

We need to understand the factors that promote species invasions in order to manage and reduce the 
damage caused by invasive species. Worldwide, invasive species are among the most important threats to biodiversity in freshwater ecosystems, particularly in lakes (Sala et al. 2000). In freshwater ecosystems, human mediated transport of organisms plays a key role in spread and introduction of invasive species (Reviewed in Havel et al. 2015). For example, in the well-studied Rhine River the number and spread of introduced invasive species has increased dramatically within the last decades (Baur and Schmidlin 2007). Human activities have increased connectedness between watersheds and promoted passive transportation and unintentional release to new areas (Leuven et al. 2009).

Natural dispersal of exclusively aquatic species is often limited by the dendritic structure of waterways (Fagan 2002). Secondary spread of non-native species to more isolated or disconnected water bodies away from the main shipping routes suggests an important role for overland transport by human activities (Johnson et al. 2001; Minchin et al. 2003). For example, overland transport of recreational boats has been shown to function as a vector for surface-fouling zebra mussels (Johnson et al. 2001). Within-lake movement of recreational boats has also been shown to function as a strong vector for the secondary spread of zooplankton and benthic invertebrates (Kelly et al. 2013). However, the headwaters of European river systems are strongly isolated by dams and rarely used for commercial shipping. Nevertheless, many introductions to these freshwater systems have occurred (Bacela-Spychalska et al. 2013; Kinzelbach 1992). It seems then that overland transport is a prerequisite for the spread of non-native species among these headwaters. As commercial boats are rarely transported overland, transport of recreational boats remains the most likely distribution vector (Bacela-Spychalska et al. 2013; Johnson et al. 2001; Kelly et al. 2013; Rothlisberger et al. 2010).

Zebra mussel (Dreissena polymorpha, Pallas 1771) represents an invasive species that has benefitted from human activities. The zebra mussel has spread widely across western Europe since the early nineteenth century (Kinzelbach 1992) and has now colonized most larger rivers and lakes except for highest elevation headwaters. It originates from the PontoCaspian region, which is now well connected to Western Europe via three inland channels for commercial shipping (Bij de Vaate et al. 2002). Overland dispersal is also likely to have occurred as adult zebra mussels ( $>10 \mathrm{~mm}$ shell length) can survive up to 10 days out of water (Ricciardi et al. 1995; Paukstis et al. 1999). Thus they have the potential to survive overland transport over long distances and colonize new habitats far from invaded source regions.

Indeed, Johnson and Carlton (1996) and Johnson et al. (2001) showed that overland transport of mussels fouling boat equipment and macrophytes attached on the recreational boats enabled the overland transport of zebra mussels to isolated lakes even when the hulls of the boats were not fouled. Both studies focused more on the potential of trailer-kept ("transient") boats to transport zebra mussels over land and less on the boats moored in harbors and marinas over longer periods of time. However, as these authors recognized, mussel fouling directly on the hulls of boats that are kept permanently in water is more likely, and therefore we hypothesize that these boats can also be important as vectors for zebra mussels, even if they might be transported less frequently (Minchin et al. 2006). It is thus important to know the vector potential (the potential of a specific distribution vector to transport non-native species, such as zebra mussels, to new habitats) of different boat types, and how different boat properties and boating practices contribute to the invasion risk associated with overland transport events.

This study addresses this research gap by examining the vector potential of recreational boats that are primarily moored and rarely transported overland for distributing invasive species. The study focuses on transportation of recreational boats in Switzerland and quantifies two key aspects of those that are mostly kept in water: (1) the rate of fouling by zebra mussels and (2) the frequency that they are transported between water bodies in Switzerland. Given that the transport of this type of boat is a rare event, we used a methodology for this study that allows investigating a very large sample efficiently. Specifically, we implemented a large-scale representative survey of boat owners in Switzerland. Due to the risks of biases in self-reported data, we also sampled boats using launch ramps and boats moored in harbors. Finally, because our field sampling showed that mussels on boat hulls were mostly juveniles (1-10 $\mathrm{mm}$ in shell length), we experimentally tested how long this size of zebra mussel survives out of water at two temperature regimes. We estimated the vector potential of 
recreational boats in Switzerland based on which boat categories were fouled with mussels, how frequently they were transported, the classes of water bodies involved, and the time period of the transportation. Moreover, by investigating the transportation routes between different water bodies, we asked specifically if zebra mussels are being transported to small alpine lakes that have not been colonized by zebra mussels so far. Finally, we discuss our results in the context of prevention and management of possible future invasions by fouling invasive species, for example, the quagga mussel (Dreissena rostriformis bugensis, Andrusov 1897), which has not yet spread to the lakes of this study. Our research not only provides new information on the prevalence of mussel fouling and transport of recreational boats in Switzerland, but proposes that it might, at least in some areas, not be the most frequently transported boats that spread invasive species but the least often transported ones.

\section{Methods}

\section{Study area}

We studied boats used on navigable lakes and rivers of Switzerland (Fig. 1), representing headwaters of the wider alpine region. Zebra mussels occur in almost all larger lakes and rivers in Switzerland, except those at higher altitudes (Fig. 1). To date, the highest lake in Switzerland, where zebra mussels have been found, is on 1250 m.a.s.l.. Commercial shipping between lakes is absent in Swiss waters, but lakes are used intensively for recreational boating with a total of 99,200 private boats registered at cantonal offices in 2013 (Swiss Federal Statistical Office 2014). These boats are distributed over roughly 30 navigable lakes and several rivers and are almost exclusively used for recreational purposes.

\section{Questionnaire}

We mailed boat owners self-administered questionnaires (in German and French) that could be filled out on paper or on the internet. The request indicated that participation was voluntary and provided information about the study as well as how the investigators could be contacted in case of questions. The questionnaire consisted of 30 questions about socio-demographic information, the boat characteristics, the presence of fouling organisms on exterior surfaces, the overland transport between water bodies, the cleanliness of the boat and cleaning behavior, and attitudes towards cleaning the boat. Filling out the questionnaire took about $15 \mathrm{~min}$.

Most questions used in this study were straightforward in design. For example, we simply asked where the boat was normally kept with the possible responses of (1) moored all year around, (2) moored during summer season and (3) kept on land. This third category is referred to as "transient" or "trailered" boats in other studies (e.g. Johnson et al. 2001; Rothlisberger et al. 2010). Table 1 compiles the categories of the questions used in this study. The questions on overland transport between water bodies were more complex, resulting in a separate data set that was used to analyze over land transportation frequencies, routes and durations of transport. For each of their ten most recent overland transport events, they were asked to specify the water body of origin and the destination water body, how long the boat had been in the water body of origin, for how many days the boat was out of water during transport and storage, and how long the boat remained in the destination water body. Boat owners were also asked to inform about the number of transport events within the past 5 years.

Nine of the 26 cantonal shipping agencies in Switzerland sent the questionnaires to a random sample of $20 \%$ of the registered boat owners (Supplementary Material, Fig. S1). Overall, about $10 \%$ of all registered boat owners in Switzerland $(\mathrm{N}=10,500)$ received the questionnaire. We received 3561 replies (response rate $=34 \%$ ). The relative distribution of boat types represented in the replies matched the distribution provided by the cantonal shipping agencies (Swiss Federal Statistical Office 2014), suggesting that the survey responses was representative of the population of boats registered in Switzerland. The distribution of boat types in each canton did not differ significantly between survey data and the Swiss-wide data set (Supplementary Material, Fig. S2).

Statistical analysis of the questionnaire

We used logistic regression models to evaluate which of the independent variables assessed in the questionnaire best explained the dependent variables. We used two dependent variables in separate models: mussel 


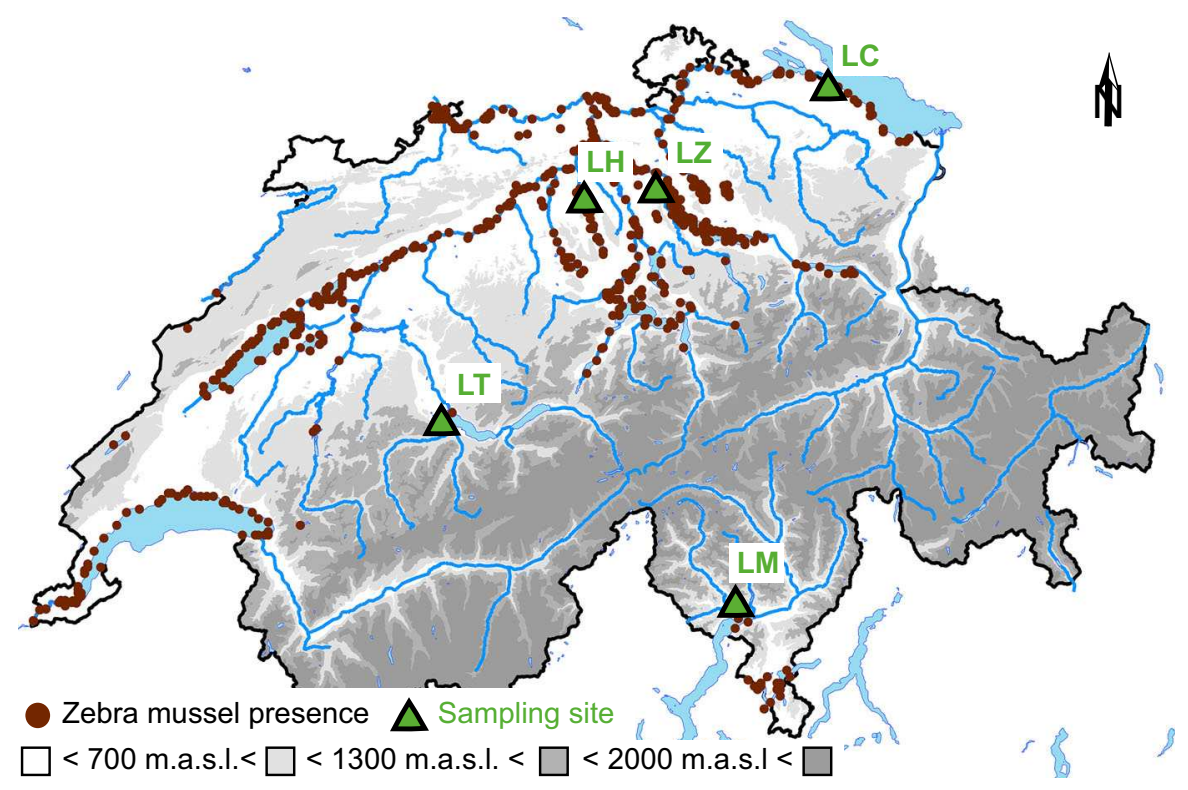

Fig. 1 Distribution of zebra mussels in 2011 in Switzerland (brown dots, zebra mussel presence data collected from cantonal offices, the Swiss Centre for the Cartography of Fauna, CSCF, and various environmental offices in Switzerland) and field sampling sites (green triangles, LC: Lake Constance, Bottighofen, $47^{\circ} 64^{\prime} 74.65^{\prime \prime} \mathrm{N}, 9^{\circ} 19^{\prime} 69.72^{\prime \prime} \mathrm{E}$, LH: Lake Hallwil,

fouling (whether boat owners had reported mussel fouling on their boat) and overland transport (whether a boat had been transported overland within the last 5 years). Only explicit answers were included in the analysis and others, such as 'don't know' or 'other option', were excluded. We performed a similar model selection procedure for both dependent variables. First, we explored the correlation structure between all explanatory variables using a categorical principal component analysis (CatPCA) in SPSS (Statistical Package for the Social Sciences, Version 21). None of the Spearman correlations between pairs of transformed explanatory variables exceeded 0.5 , indicating sufficiently low multicollinearity to perform logistic regression analyses. Subsequently, the effects of the explanatory variables were tested for both dependent variables in logistic regression models using the statistical package $\mathrm{R}$, version 3.0.2 (R-Core-Team 2014). The relevant explanatory variables were grouped in sets (Table 1) and variables of each set were first tested separately against the dependent variables. All variables with significant effects and their higher order interactions were then tested again in combined models where we added and removed
Beinwil am See, $47^{\circ} 26^{\prime} 91.83^{\prime \prime} \mathrm{N}, 8^{\circ} 21^{\prime} 15.72^{\prime \prime} \mathrm{E}, L M$ Lake Maggiore, Tenero Campofelice, $46^{\circ} 16^{\prime} 63.53^{\prime \prime} \mathrm{N}$, $8^{\circ} 85^{\prime} 42.93^{\prime \prime} \mathrm{E}, \quad L T$ Lake Thun, Thun, $46^{\circ} 73^{\prime} 41.84^{\prime \prime} \mathrm{N}$, $7^{\circ} 63^{\prime} 01.55^{\prime \prime} \mathrm{E}, L Z$ Lake Zürich, Wollishofen, $47^{\circ} 20^{\prime} 25.61^{\prime \prime} \mathrm{N}$, $8^{\circ} 32^{\prime} 22.20^{\prime \prime} \mathrm{E}$ ). All field-sampling sites lie below $700 \mathrm{~m}$ above sea level. Grey shades show different levels of altitude

explanatory variables in a stepwise procedure comparing the explanatory power of the models using AIC (Akaike information criterion) and significance levels of single variables. Since the variable "water body" consisted of many water bodies, and some of them only contained few observations, we summarized water bodies into the following categories: fresh waters abroad, ocean, rivers, large meso-eutrophic lakes $\left(\geq 38 \mathrm{~km}^{2}, \mathrm{P}_{\text {tot }}>0.03 \mathrm{mg} \mathrm{P} / \mathrm{L}\right)$, medium-sized lakes $\left(\geq 7 \mathrm{~km}^{2}\right)$, small lakes $\left(<7 \mathrm{~km}^{2}\right)$, large oligotrophic lakes $\left(\geq 38 \mathrm{~km}^{2}, \mathrm{P}_{\text {tot }}<0.03 \mathrm{mg} \mathrm{P} / \mathrm{L}\right)$ and small alpine lakes $\left(<7 \mathrm{~km}^{2}\right.$ above 1300 m.a.s.l.). Lakes were classified by trophic state based on the Hydrological Atlas of Switzerland (Liechti and Jakob 1992). In the logistic regression models for mussel fouling and transport, we excluded fresh waters abroad, oceans and small alpine lakes from the analysis due to small sample sizes (Table 2a).

The data on specific overland transport events, for which origin and destination water bodies had been named in the survey, were analyzed separately. We used Geographical Information System (GIS) to illustrate and quantitatively analyze the frequencies of overland transport between individual water bodies. 
Table 1 Survey summary showing all variables assessed in the survey and discussed in this paper

\begin{tabular}{|c|c|c|c|c|c|c|c|c|}
\hline Variable sets & Variables & \multicolumn{7}{|c|}{ Variable categories } \\
\hline Location & Water body & \multicolumn{7}{|c|}{ Water body and water body category (see text and Figs. 2,5 ) } \\
\hline Location & Boat storage type & \multicolumn{2}{|c|}{$\begin{array}{l}\text { Year-round in water } \\
22.9 \%\end{array}$} & \multicolumn{2}{|c|}{$\begin{array}{l}\text { Season in water } \\
49.6 \%\end{array}$} & \multicolumn{2}{|l|}{$\begin{array}{l}\text { Dry }^{\mathrm{a}} \\
25.2 \%\end{array}$} & $\begin{array}{l}\text { Other } \\
1.4 \%\end{array}$ \\
\hline Properties & Boat type & \multicolumn{2}{|c|}{$\begin{array}{l}\text { Motorboat } \\
50.7 \%\end{array}$} & \multicolumn{2}{|c|}{$\begin{array}{l}\text { Sailing boat } \\
39.9 \%\end{array}$} & \multicolumn{2}{|c|}{$\begin{array}{l}\text { Boat without motor }{ }^{\mathrm{b}} \\
8.2 \%\end{array}$} & $\begin{array}{l}\text { Other option } \\
1.3 \%\end{array}$ \\
\hline Properties & Motor type & \multicolumn{2}{|l|}{$\begin{array}{l}\text { Z-drive } \\
29.6 \%\end{array}$} & \multicolumn{2}{|c|}{$\begin{array}{l}\text { Shaft driven } \\
12 \%\end{array}$} & \multicolumn{2}{|c|}{$\begin{array}{l}\text { Outboarder } \\
58.4 \%\end{array}$} & $\begin{array}{l}\text { Other } \\
4.7 \%\end{array}$ \\
\hline Properties & Sailing boat type & \multicolumn{2}{|l|}{$\begin{array}{l}\text { Yole } \\
22.7 \%\end{array}$} & \multicolumn{2}{|c|}{ Keel boat } & \multicolumn{2}{|c|}{ Catamaran } & $\begin{array}{l}\text { Other type } \\
5.3 \%\end{array}$ \\
\hline Properties & Boat material & \multicolumn{2}{|l|}{ Wood } & \multicolumn{2}{|c|}{ Glass fiber } & Aluminium & & $\begin{array}{l}\text { Other material } \\
4.5 \%\end{array}$ \\
\hline Properties & Boat length & \multicolumn{2}{|c|}{$\begin{array}{l}0-2.5 \mathrm{~m} \\
1.8 \%\end{array}$} & \multicolumn{2}{|c|}{$\begin{array}{l}2.6-6.5 \mathrm{~m} \\
57.2 \%\end{array}$} & \multicolumn{2}{|c|}{$\begin{array}{l}6.6-10 \mathrm{~m} \\
34.8 \%\end{array}$} & $\begin{array}{l}>10 \mathrm{~m} \\
4.6 \%\end{array}$ \\
\hline Usage & Boat usage & \multicolumn{2}{|l|}{$\begin{array}{l}\text { Pleasure } \\
82.5 \%\end{array}$} & \multicolumn{2}{|c|}{$\begin{array}{l}\text { Competition } \\
10.3 \%\end{array}$} & Fishing & & $\begin{array}{l}\text { Water sport } \\
13.5 \%\end{array}$ \\
\hline Usage & Launching infrastructure & \multicolumn{2}{|l|}{$\begin{array}{l}\text { Crane } \\
38.2 \%\end{array}$} & \multicolumn{2}{|l|}{ Ramp } & $\begin{array}{l}\text { Nothing } \\
15.8 \%\end{array}$ & & $\begin{array}{l}\text { Other } \\
4.9 \%\end{array}$ \\
\hline Prevention & Antifouling paint & \multicolumn{2}{|c|}{$\begin{array}{l}\text { Yes } \\
67.4 \%\end{array}$} & \multicolumn{2}{|l|}{ No } & $\begin{array}{l}\text { Don't k } \\
7.5 \%\end{array}$ & & \\
\hline Cleaning & Cleaning location & \multicolumn{2}{|c|}{$\begin{array}{l}\text { Shipyard/public station } \\
38.5 \%\end{array}$} & \multicolumn{2}{|c|}{$\begin{array}{l}\text { In the water } \\
8.2 \%\end{array}$} & \multicolumn{2}{|c|}{$\begin{array}{l}\text { At land } \\
26 \%\end{array}$} & $\begin{array}{l}\text { At home } \\
23.2 \%\end{array}$ \\
\hline Cleaning & Reaction to fouling & \multicolumn{2}{|l|}{$\begin{array}{l}\text { No react } \\
8.3 \%\end{array}$} & \multicolumn{2}{|c|}{$\begin{array}{l}\text { Removed all } \\
74.1 \%\end{array}$} & $\begin{array}{l}\text { Tried } \mathrm{r} \\
14.6 \%\end{array}$ & ving & $\begin{array}{l}\text { Other reaction } \\
2.9 \%\end{array}$ \\
\hline Fouling & Mussel fouling & $\begin{array}{l}\text { Yes } \\
35 \%\end{array}$ & & $\begin{array}{l}\text { No } \\
65 \%\end{array}$ & & & & \\
\hline Fouling & Fouling area & $\begin{array}{l}\text { Boat hu } \\
62.2 \%\end{array}$ & & $\begin{array}{l}\text { Motor } \\
38.1 \%\end{array}$ & & $\begin{array}{l}\mathrm{Keel} / \mathrm{S} \\
25.5 \%\end{array}$ & & $\begin{array}{l}\text { Water in boat } \\
0.9 \%\end{array}$ \\
\hline Transport & $\begin{array}{l}\text { Overland transport } \\
\text { (events/5 years) }\end{array}$ & $\begin{array}{l}0 \\
88.8 \%\end{array}$ & $\begin{array}{l}1-4 \\
7.4 \%\end{array}$ & $\begin{array}{l}5-8 \\
1.6 \%\end{array}$ & $\begin{array}{l}9-12 \\
0.6 \%\end{array}$ & $\begin{array}{l}13-16 \\
0.2 \%\end{array}$ & $\begin{array}{l}17-20 \\
0.2 \%\end{array}$ & $\begin{array}{l}>20 \\
1.2 \%\end{array}$ \\
\hline
\end{tabular}

The relevant variables were grouped in sets (such as mussel fouling, overland transport, boat location, boat properties, boat usage and boat cleaning). In the model selection process, independent variables of each set were first tested separately against the dependent variables (see methods: statistical analysis of the survey data). For each variable, the response categories and the corresponding proportions are shown. Explanations on selected variables: ${ }^{a}$ Dry stored boats are mostly kept on a trailer, at home or in a storage facility. They are only launched when used, mostly for rather short periods of time (hours-several days). ${ }^{\mathrm{b}}$ Boats without motor are the boats belonging to neither of the two categories rowing boats and motorboats, but were mostly wooden boats, rowing boats or flat bottomed or punt-like boats

Subsequently, we investigated how long boats were kept out of water during overland transport and quantified transport frequencies between water body categories.

\section{Field sampling}

To verify the mussel fouling rates reported in the questionnaire, we investigated frequency and intensity of mussel fouling on recreational boats by inspecting boats and sampling hulls in five lakes (Fig. 1, Lake Constance and Lake Zürich, two large mesotrophic lakes, Lake Thun, a large oligotrophic lake, Lake Hallwil, a medium eutrophic lake and Lake Maggiore, a large mesotrophic lake south of the alps) over the months of June, July and August 2013. In order to include both, boats kept on land and boats year-round or seasonally moored, we used two different assessment methods. 
Table 2 Results of the final logistic regression models with (a) mussel fouling on boats (whether boat owners reported mussel fouling in the survey) and (b) overland transport of boats (whether boat owners reported an overland transport within the last 5 years) as dependent variables

\begin{tabular}{|c|c|c|c|c|c|c|c|}
\hline \multicolumn{8}{|c|}{ Dependent variable: mussel fouling yes/no } \\
\hline Independent effects & LR Chisq & $d f$ & $P$ value & Sig. & Categories & $\mathrm{N}$ fouled & $\%$ fouled \\
\hline \multicolumn{8}{|l|}{ (a) } \\
\hline Water body category & 241.46 & 4 & $<0.0001$ & $* * *$ & Figure $2 \mathrm{a}$ & & \\
\hline \multirow[t]{3}{*}{ Boat storage } & 653.9 & 2 & $<0.0001$ & $* * *$ & Year round in water & 503 & 60.3 \\
\hline & & & & & Seasonal in water & 729 & 40.5 \\
\hline & & & & & Dry location & 26 & 2.9 \\
\hline \multirow[t]{3}{*}{ Boat type } & 10.73 & 2 & $<0.005$ & $* *$ & Motor boat & 581 & 32.1 \\
\hline & & & & & Sailing boat & 574 & 40.1 \\
\hline & & & & & Without motor & 76 & 26.9 \\
\hline \multirow[t]{2}{*}{ Water sports } & 8.78 & 1 & $<0.005$ & $* *$ & Yes & 112 & 22.7 \\
\hline & & & & & No & 1154 & 37.0 \\
\hline \multirow[t]{2}{*}{ Fishing } & 8.45 & 1 & $<0.005$ & $* *$ & Yes & 268 & 42.1 \\
\hline & & & & & No & 997 & 33.5 \\
\hline Boat storage $\times$ boat type & 10.29 & 4 & $<0.05$ & $*$ & & & \\
\hline
\end{tabular}

Dependent variable: boat transport yes/no

\begin{tabular}{lllllll}
\hline Independent effects & LR Chisq & $d f$ & $P$ value & Sig. & Categories & N transported $\%$ transported \\
\hline
\end{tabular}

(b)

\begin{tabular}{|c|c|c|c|c|c|c|c|}
\hline Water body category & 26.16 & 4 & $<0.0001$ & $* * *$ & Figure $2 b$ & & \\
\hline \multirow[t]{3}{*}{ Boat storage } & 56.48 & 2 & $<0.0001$ & $* * *$ & Year round in water & 52 & 6.1 \\
\hline & & & & & Seasonal in water & 163 & 8.8 \\
\hline & & & & & Dry & 198 & 21.2 \\
\hline \multirow[t]{3}{*}{ Boat type } & 8.91 & 2 & $<0.05$ & $*$ & Motor boat & 192 & 10.3 \\
\hline & & & & & Sailing boat & 197 & 13.4 \\
\hline & & & & & Without motor & 18 & 6.1 \\
\hline \multirow[t]{2}{*}{ Water sports } & 6.14 & 1 & $<0.05$ & $*$ & Yes & 77 & 15.2 \\
\hline & & & & & No & 340 & 10.6 \\
\hline \multirow[t]{2}{*}{ Competitions } & 73.23 & 1 & $<0.0001$ & $* * *$ & Yes & 108 & 28.0 \\
\hline & & & & & No & 309 & 9.3 \\
\hline Boat storage $\times$ boat type & 15.36 & 4 & $<0.01$ & $*$ & & & \\
\hline
\end{tabular}

The columns show the included independent variables, the Likelihood Ratio Chi square statistics for each effect (LR Chisq), the degrees of freedom $(d f)$, corresponding $P$ values, significance levels (Sig.) variable categories, and for each category the number of boats fouled ( $\mathrm{N}$ fouled) in (a) or transported ( $\mathrm{N}$ transported) in (b), respectively, and percent of boats fouled in a) or transported in b), respectively. The odds ratios and the corresponding confidence intervals are presented in the supplementary material (Supplementary Material, Table S1)

For boats kept on land, we visited public boat ramps during sunny weekends, and inspected all boats being launched or taken out of the water during the time we were present at the ramp (total $\mathrm{N}=119$ boats). We also asked the owners of the inspected boats where they normally kept their boat, where they had transported their boat from and how long their boat had been kept in water before our inspection. We estimated the amount of zebra mussels and other organisms visible to the naked eye by inspecting all surfaces of the boat including the engine and niche areas (crevices, seams and rivets) on the outside of the boat. Additionally, we 
checked for macrophytes attached to the boat (Johnson et al. 2001). To check for very small mussels and other small organisms, we scraped an area of $20 \times 20 \mathrm{~cm}^{2}$ of any boat that had visible fouling (14 out of 119 boats). These samples were kept in $70 \%$ ethanol and subsequently analyzed using a dissecting microscope (magnification: $5 \times-40 \times$ ).

For boats moored year-round or seasonally, we directly inspected 30 boats per lake underwater in August 2013 (Fig. 1). In a first step, we snorkeled around the boat and estimated the amount of mussels visible by eye or by touch at the boat hull, around the motor, or at the keel/sword. In a second step, we pooled samples from different surfaces of the boat (one each from the hull, the motor, and the keel/sword area) taken while snorkeling. Surfaces were scraped and the removed material caught with a zooplankton net $(250 \mu \mathrm{m}$ mesh size). We aimed at scraping off about the same area per boat as for the sampling at boat ramps (an area of roughly $20 \times 20 \mathrm{~cm}^{2}$ ). Samples were transported to the lab in a cooler and analyzed using a dissecting microscope within $24 \mathrm{~h}$. The samples were checked for zebra mussels and other animals that could originate from the boat hull. The shell length of five individual zebra mussels per life cycle stage (plantigrade larva, juveniles and adult mussels) was measured for five boat samples per site.

We examined the effect of boat type (sailing boat, motor boat), and water body (Lake Zürich, Lake Hallwil, Lake Thun, Lake Constance and Lake Maggiore) on mussel fouling (presence/absence) in a logistic regression model in R (R-Core-Team 2014).

\section{Survival experiment}

As we found mainly small mussels on the inspected boats, we experimentally tested survival of juvenile mussels (shell length: $1-10 \mathrm{~mm}$ ) to aerial exposure. We installed 48 plastic disks in Lake Greifen (coordinates: $47^{\circ} 20^{\prime} 58^{\prime \prime} \mathrm{N}, 8^{\circ} 40^{\prime} 49^{\prime \prime} \mathrm{E}$ ) on which zebra mussel larvae settled and grew between July and September 2013. Disks were then retrieved from the lake and transported to the lab in a cooler. Within $6 \mathrm{~h}$, the number of mussels was counted for each disk using a dissecting microscope (magnification $5 \times-40 \times$ ) and the shell length of 20 haphazardly chosen individuals per disk was measured to evaluate the size range of the mussels. Mussels shell length ranged between 1 and $13 \mathrm{~mm}$ with a median of $3.7 \mathrm{~mm}$ and the size distribution on the settlement plates did not differ between treatments and time points. Subsequently the mussel-fouled disks were kept in air in two different environmental chambers at 12 and $25{ }^{\circ} \mathrm{C}$ with a similar range of humidity (70-80\%). The average day temperature in Zürich, Switzerland, in July is $25^{\circ} \mathrm{C}$, while $12{ }^{\circ} \mathrm{C}$ represents the average day temperature in early spring or late autumn (http://www.climatedata. eu). After 18, 42, 66 and $90 \mathrm{~h}$, four disks per temperature treatment were randomly chosen and the number of alive and dead mussels was identified under the dissecting microscope. A mussel was scored as dead when its shell was open and no movement was detected upon physical stimulation (Paukstis et al. 1999). As a positive control, three disks were kept in aerated lake water in each environmental chamber and assessed for mussel survival at each time point.

\section{Results}

Descriptive statistics of the questionnaire

Table 1 summarizes the results of the questionnaire for the relevant variables discussed in this paper. The "home" water bodies, where the boats were normally kept, are not shown in the table. In total, 42 water bodies of variable sizes were listed. The number of boats varied largely between water bodies between 1 (Lake Davos) and 670 (Lake Geneva). As 47 different water bodies were reported in the questionnaire and it was difficult to analyze and interpret the results for each location separately, we grouped the water bodies into categories as described in the method section. After grouping we included five out of eight categories of locations for the statistical analysis: rivers (275 boats), large meso-eutrophic lakes (2160 boats), medium lakes (425 boats), small lakes (24 boats), and large oligotrophic lakes (436 boats). Small alpine lakes ( 3 boats) were not included in the analysis but are still shown in the figures as a separate category (Figs. 2, 5).

\section{Mussel fouling}

In total $35 \%$ of the boat owners stated that they had found zebra mussels on their boat. Within this group, two-thirds had found mussels at the boat hull while many also reported that mussels were found in the 
Fig. 2 Percentage of boats for which boat owners reported: a mussels growing on their boat (mussel fouling $=$ yes) and no mussels growing on their boat (mussel fouling $=$ no) and $\mathbf{b}$ whether they had transported

(transport $=$ yes) or not transported (transport $=$ no) their boat at least once overland within the last 5 years. Within each bar the different shades of grey represent boat storage types: boats moored year-round (black), moored seasonally (grey) and boats kept on land (white). Percentages are shown separately for each of the water body categories rivers, large meso-eutrophic lakes $\left(\geq 38 \mathrm{~km}^{2}\right.$,

$\mathrm{P}_{\text {tot }}>0.03 \mathrm{mg} \mathrm{P} / \mathrm{L}$ ), medium sized lakes $\left(\geq 7 \mathrm{~km}^{2}\right)$, small lakes $\left(<7 \mathrm{~km}^{2}\right)$, large oligotrophic lakes $\left(\geq 38 \mathrm{~km}^{2}\right.$,

$\left.\mathrm{P}_{\text {tot }}<0.03 \mathrm{mg} \mathrm{P} / \mathrm{L}\right)$ and small alpine lakes $\left(<7 \mathrm{~km}^{2}\right.$, above 1300 m.a.s.1.)

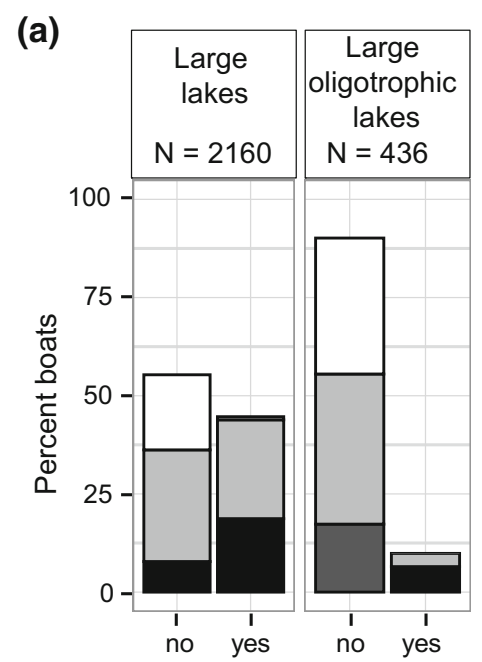

(b)

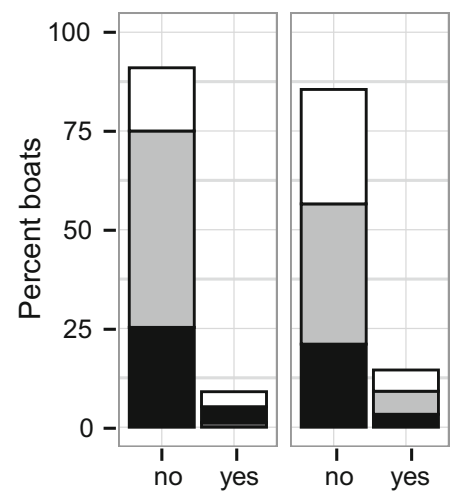

Boat storage type:
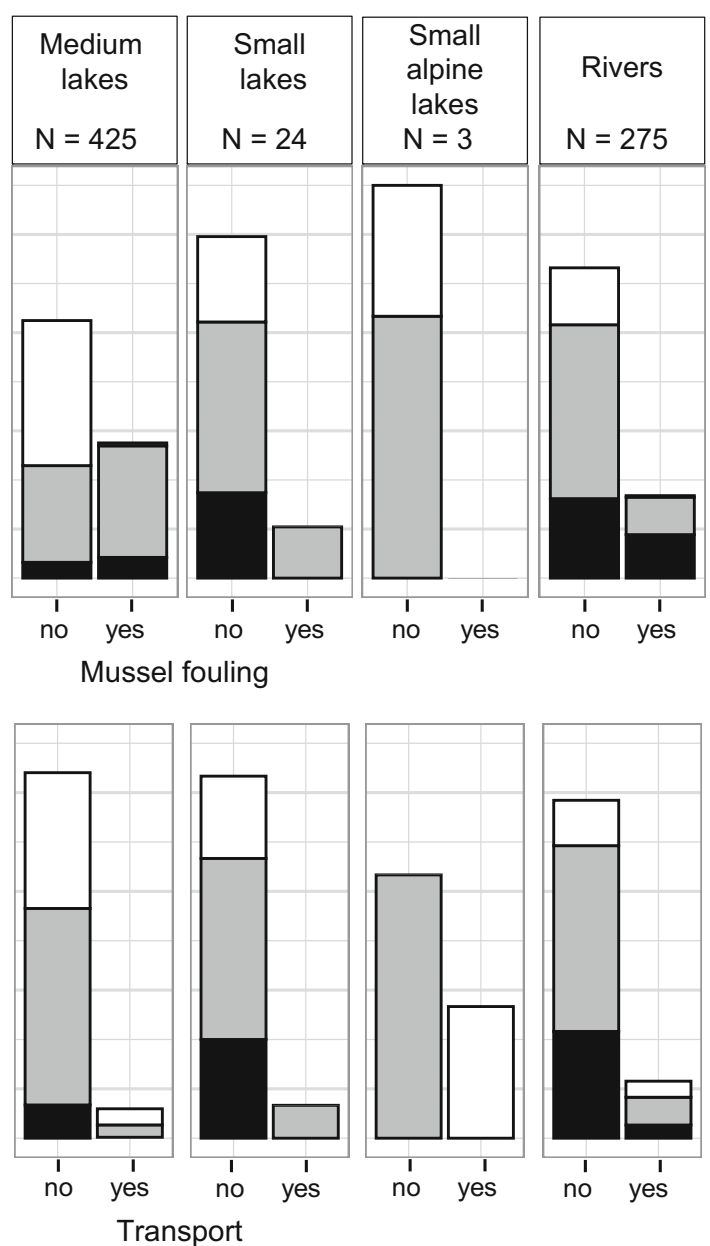

$\square$ On land $\square$ Seasonally moored

Year-round moored

engine area $(38 \%)$ and niche areas around the keel or sword (26\%). Boat owners also mentioned the cooling system, fish bucket and rudder as frequently fouled areas.

The best-fitting logistic regression model for mussel fouling included boat storage, water body category, boat type, water sports, fishing and the two-way interaction between boat storage and boat type as explanatory variables $\quad(\mathrm{AIC}=3143.6, \quad$ residual deviance $=3111.6$ on $3096 d f$ ). Boats that stayed throughout the year in the water were more likely to be fouled by mussels $(60 \%)$ than boats seasonally kept in water $(40 \%)$, whereas boats that were kept on land were rarely fouled by zebra mussels (2.9\%, $P<0.0001$, Table 2a). The probability of mussel fouling was higher in the large and medium size eutrophic lakes and varied significantly between water body categories $(P<0.0001$, Table 2a; Fig. $2 \mathrm{a})$. Although not analyzed in detail, single water bodies varied considerably in the mussel fouling rates (between $0 \%$ in Lake Brienz and $63 \%$ in Lake Pfäffikon). Two weaker but significant predictors of mussel fouling were boat type and the interaction between boat type and boat storage (for details see Supplementary Material, Fig. S3). Boats used for water sports had less mussel fouling while the boats used for fishing were fouled more frequently (Table 2a). Reported mussel fouling was also consistently higher in boats which were painted with antifouling (Supplementary Material Fig. S4). This counterintuitive result may be due to the fact, that boat owners who often have problems with mussel fouling 
are more likely to use antifouling paint. As the use of antifouling may be strongly dependent on the likelihood of mussel fouling (rather than the other way around) we excluded antifouling as an explanatory variable from the model.

The biological sampling confirmed that the type of boat storage and the type of water body are important for mussel fouling. None of the 119 boats inspected at boat ramps were fouled with mussels and no zebra mussels or other aquatic animals of interest were found in the 14 biofilm samples we collected at the boat ramps. Most of the inspected boats had been in the water only for a short period of time (1-3 days) before the examination and were normally kept on a trailer $(85 \%)$. We also did not find any macrophytes entangled on any of these inspected boats and trailers. In contrast, the 150 underwater samples scraped from boat hulls revealed a mussel fouling rate that was comparable to the questionnaire for boats kept in water either seasonally or all year around (41\% in underwater samples vs. $44 \%$ in the questionnaire, Fig. 3). The presence of mussels in the biological samples was also highly dependent on the sampled water body (Chi square $=64.7, d f=4, P<0.0001)$, but it was independent of boat type (Chi square $=0.46, d f=2$, $P=0.79$ ). On average, boats of all lakes carried rather small mussels (between 0.5 and $4 \mathrm{~mm}$ long), and we only found larger mussels (up to $2 \mathrm{~cm}$ ) on boats in Lake Zürich. For most fouled boats, mussels were found on all exterior surfaces in contact with water such as the boat hull, the engine area and the keel, independent of boat type, boat material or motor type. Numbers of mussels estimated from our underwater samples ranged from less than 100 (for $42.9 \%$ of fouled boats) to several 1000 (for $23.3 \%$ of fouled boats) per $\mathrm{m}^{2}$. Besides mussels, we found also other organisms such as bryozoan resting stages (statoblasts) or egg clutches of benthic invertebrates, but hardly any other benthic invertebrates such as the amphipod Dikerogammarus villosus.

\section{Overland transport frequencies of boats}

In our questionnaire, $11.4 \%$ of boat owners stated that they have transported their boat between water bodies at least once within the last 5 years and we calculated an average of 1.2 transport events per year within this group. The best logistic regression model explaining overland transport probability included boat storage
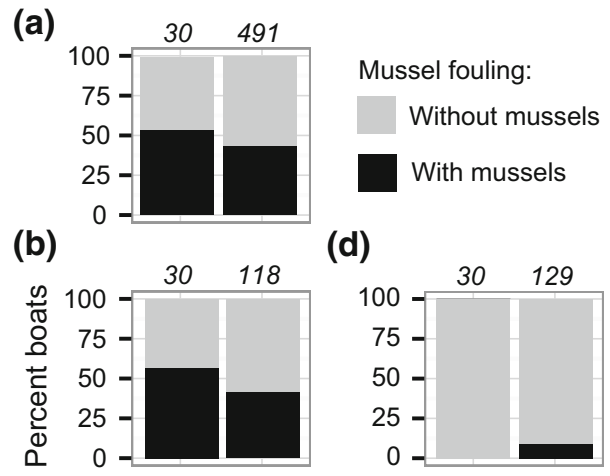

(d)

(c)
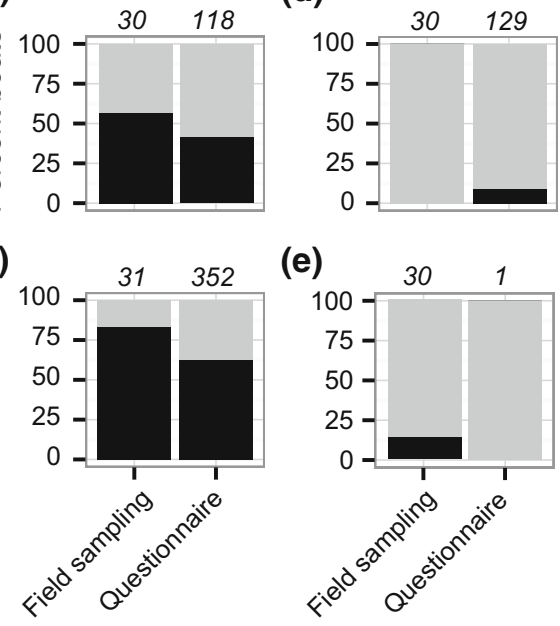

(e)

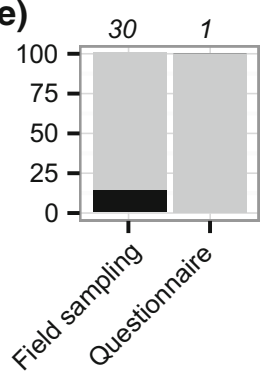

Fig. 3 Percentages of boats on which zebra mussels were found (black bars) or not found (grey bars) for our under-water sampling (one harbor per lake) and the survey data on boats which were kept in water seasonally or year-round. Percentages are given for each of the five Lakes a Lake Constance, $\mathbf{b}$ Lake Hallwil, c Lake Zürich, d Lake Thun and e Lake Maggiore. For each lake and each assessment method, the number of boats (N) represents $100 \%$ of boats assessed (for the field sampling) or $100 \%$ of boats for which either presence or absence of mussels was reported (for the questionnaire data)

type, water body category, boat type, water sports, competitions, and the two-way interaction between boat storage and boat type (AIC $=1922.2$, residual deviance $=1892.2$ on $3206 d f$ ). As for mussel fouling, the probability of transport depended again the most on the boat storage type $(P<0.0001$, Table $2 \mathrm{~b})$, but in this case, boats that were kept on land had a higher probability of being transported $(21.2 \%)$ than seasonally or year round moored boats ( 8.8 and $6.1 \%$ respectively). Furthermore, the transport probability was significantly different among the water body categories $(P<0.0001$, Table $2 b)$ being higher for boats from large oligotrophic lakes and rivers compared to the other categories (Figs. 4, 5).

Weaker significant effects on transport probability were found for boat type $(P<0.02$, Table $2 b)$ and for the interaction between storage type and boat type $(P<0.05$, Table $2 b)$. Among year-round and 


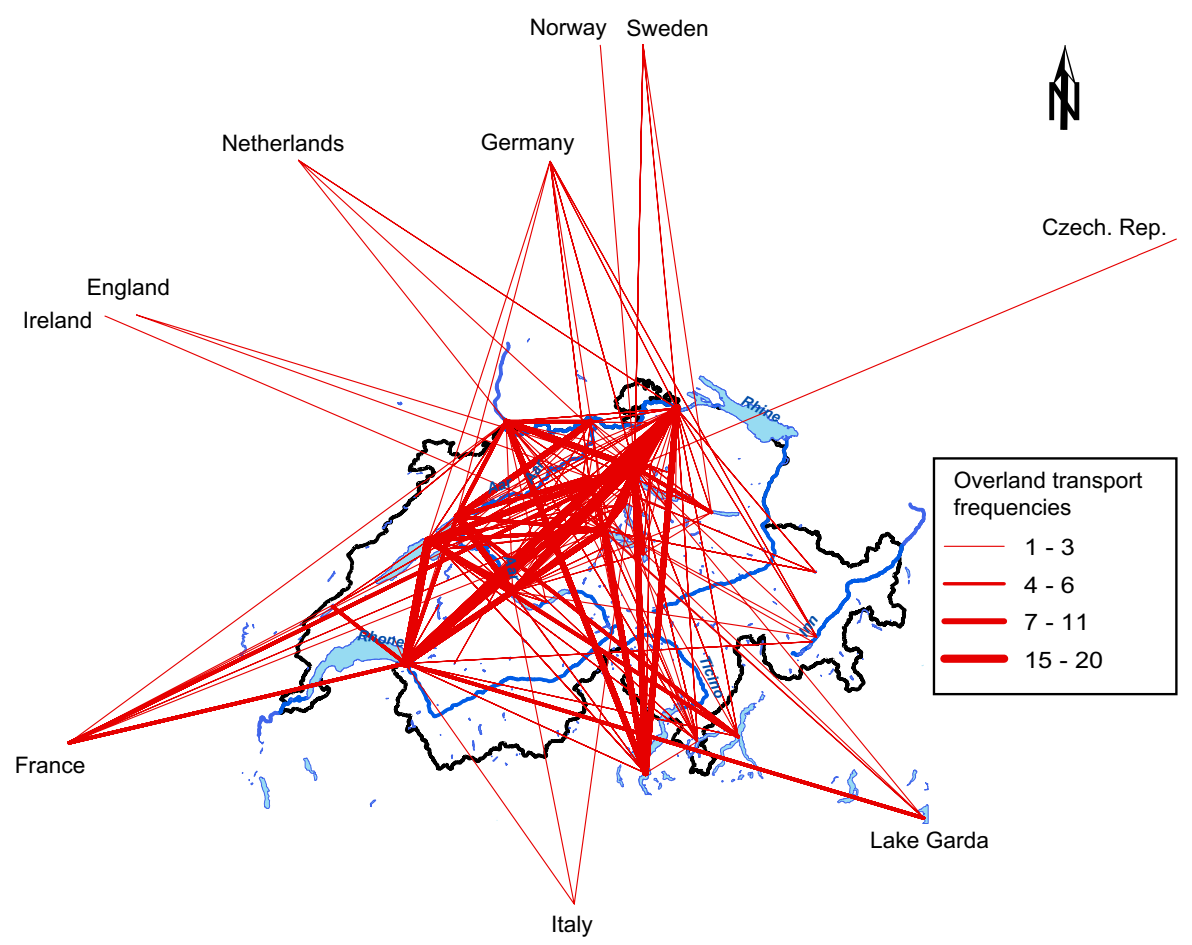

Fig. 4 Overland transport network based on survey data including all named overland routes with given start and end water bodies. The network contains only transport events between different fresh water bodies and frequencies (numbers

seasonally moored boats, the transport probabilities were elevated for sailing boats and motor boats and significantly lower for boats without motors (with probabilities of $8.1,8.3$ and $3.7 \%$, respectively). Sailing boats were only significantly more often transported over land among boats kept on land (with transport probabilities of $29.5 \%$ for sailing boats, compared to $17.4 \%$ for motor boats and $9.8 \%$ for boats without motor). Furthermore, boats used for water sports and competition were more likely to be transported (Table 2b), but only 13.5 and $10.3 \%$ of boats belonged to these categories, respectively.

Transportation routes and time spent in transport

In the questionnaire, a total of 745 overland transport events between water bodies within the past 5 years were reported. The routes and frequencies of the reported transport events among freshwaters are shown in the transport network including a total of 40 different water bodies (Fig. 4). The main transport routes are between Lake Zürich, Lake Geneva, Lake of events in past 5 years as reported in surveys) of transport routes are symbolized by the thickness of the lines. Connections to water bodies abroad were summarized to the ten categories named in the figure

Constance, Lake Neuchatel and Lake Maggiore. Almost all navigable water bodies were named at least once in the transport network. Results of the questionnaire also showed that transport events to and from abroad took place frequently.

Among all transported boats, $71 \%$ of overland transport events lasted less than 10 days and $50 \%$ lasted less than 2 days. When we analyzed the number of transport events between different water body categories that lasted less than 2 days, most occurred between different large meso-eutrophic lakes and from large meso-eutrophic to medium-sized lakes (for seasonally moored boats, Fig. 5b) and freshwaters abroad (for boats kept on land, Fig. 5c). Among moored boats, a relatively high proportion of boats was transported from large or medium-sized lakes and rivers, which indicates a higher probability of mussel transport to target lakes (Fig. 5a and b, see discussion). The few mussel-free, small alpine lakes were also a destination for such transport events, even if only rarely (Fig. 5b, seven events from medium sized and large meso-eutrophic lakes had been reported for 
(a)

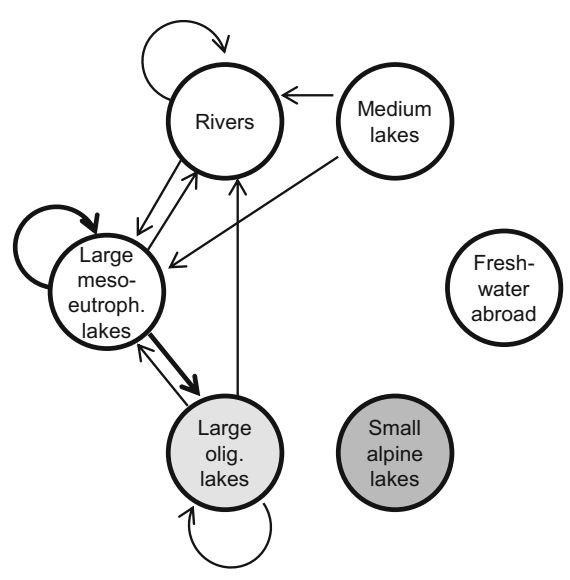

(c)

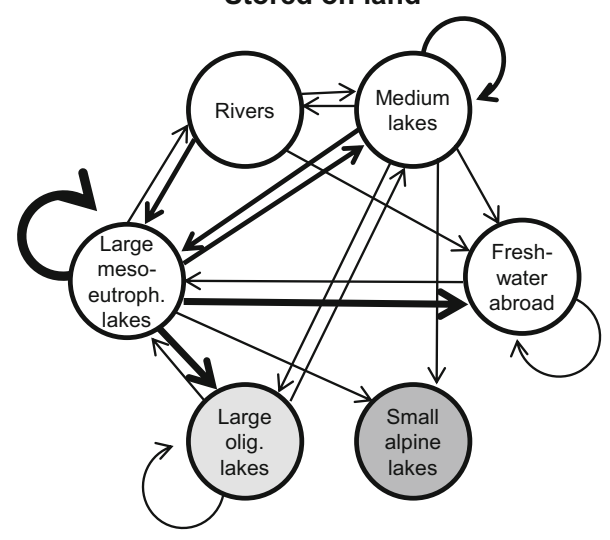

(b)

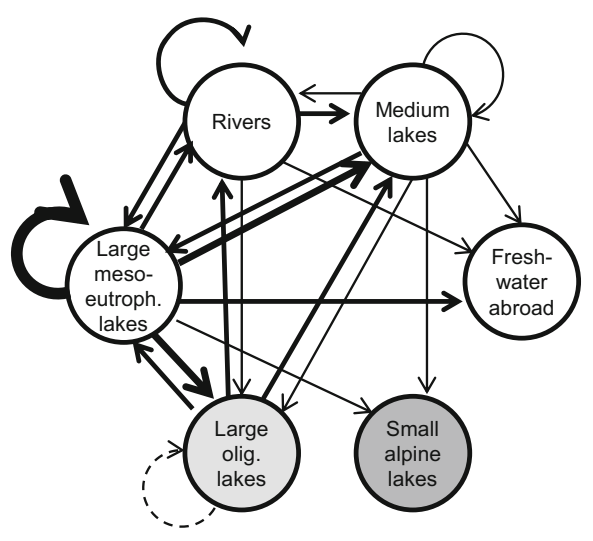

Transport events

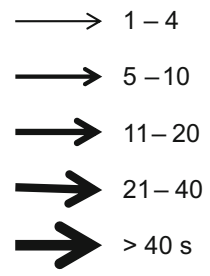

Fig. 5 Number of transport events from one water body to another grouped as transport events between different categories of water bodies such as rivers, large meso-eutrophic lakes $\left(\geq 38 \mathrm{~km}^{2}, \mathrm{P}_{\text {tot }}>0.03 \mathrm{mg} \mathrm{P} / \mathrm{L}\right)$, medium sized lakes $\left(\geq 7 \mathrm{~km}^{2}\right)$, small lakes $\left(<7 \mathrm{~km}^{2}\right)$, large oligotrophic lakes $\left(\geq 38 \mathrm{~km}^{2}\right.$, $\left.\mathrm{P}_{\text {tot }}<0.03 \mathrm{mg} \mathrm{P} / \mathrm{L}\right)$, small alpine lakes $\left(<7 \mathrm{~km}^{2}\right.$, above 1300 m.a.s.l.) and freshwater abroad. The number of transport events, as they were reported in the questionnaire for the past

seasonally moored boats). On the other hand, the large oligotrophic lakes, of which only one is still free of zebra mussels, are often a target for transport events of moored boats.

\section{Survival experiment}

Survival of juvenile mussels subjected to desiccation stress was between 1 and 2 days at $25^{\circ} \mathrm{C}$ and between 2 and 4 days at $12{ }^{\circ} \mathrm{C}$ (Supplementary Material, Fig. S5). At $25{ }^{\circ} \mathrm{C}$ most mussels were still alive after

5 years, is shown as thickness of the arrows between circles (0-4 events: 1 pt., 5-10: 2 pt., 11-20: 3 pt., 21-40: 4 pt, 40: 5 pt). Only boats which were kept 2 days or less out of water during the transport for boats moored a year-round, b seasonally and c stored on land were included. The dark grey circle represents the small alpine lakes, which are still free of zebra mussels, and the light grey circle represents the large oligotrophic lakes, of which only one is still free of zebra mussels

1 day but almost all of them had died after 2 days while at $12{ }^{\circ} \mathrm{C}$ mussel survival declined more slowly and some mussels survived up to 3 days.

\section{Frequency of high-risk boat transport}

We defined high-risk boat transfers as boats that are fouled by mussels, transported over land, and launched into the water within a time period when mussel survival is likely. We found mussel fouling to be largely determined by the boat being kept in the water 


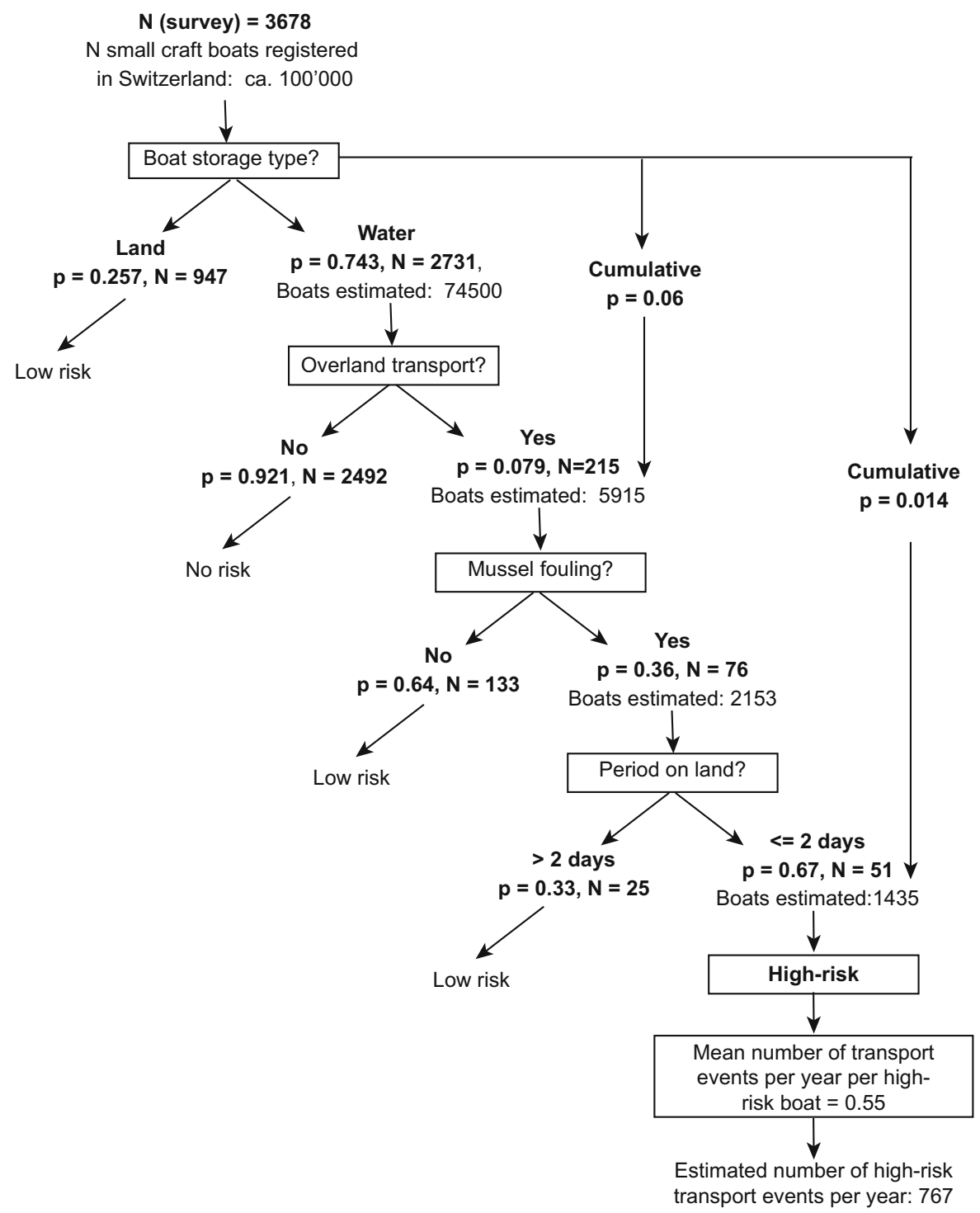

Fig. 6 Decision tree showing how we estimated the number of high-risk overland transport events between water bodies within Switzerland. We used four criteria (in boxes) to filter the data to estimate the proportion of high-risk boats for overland spread of zebra mussels. The resulting categories (bold), with proportions, the resulting numbers of boats from the survey (bold), the

(Table 2a). Based on our analysis the probability for a boat to be moored, transported and simultaneously fouled with mussels is $2.2 \%$ (Fig. 6). Furthermore, we found that $67 \%$ of all moored boats, when transported overland, are launched within less than 2 days out of water. We used 2 days as a threshold because we found small mussels on most moored boats and larger mussels $(>10 \mathrm{~mm})$ only on relatively estimated number of boats in Switzerland (regular) after selection with cumulated criteria are presented after each step. At each step the few boats for which we did not have an answer to the corresponding question (NA's) were ignored to calculate the percentages and they are also not shown in the figure

few boats and because most small mussels died between day one and day two of our experiment while almost none survived more than 2 days. Based on this assumption we estimated that $1.4 \%$ of all boats in Switzerland are high-risk boats (note that using a much more conservative level of the period on land of 1 day or less would reduce our estimate by only $39 \%$, i.e., $0.85 \%$ of all boats). On average, boats belonging 
to this high-risk group were reported to be transported 0.55 times per year. Considering that there are approximately 100,000 recreational boats in Switzerland (Swiss Federal Statistical Office 2014), we estimate that around 800 overland transport events between Swiss water bodies take place every year that present a high risk of new mussel introductions (Fig. 6).

\section{Discussion}

The focus of previous research has been on boats transported with high frequency and kept on land (often on a trailer) for most of the time. However, our results demonstrate that this class of boats is not an important vector for the spread of the zebra mussel in Switzerland. We found that the main responsible factor for the spread of zebra mussels is likely the rarely transported boats that are moored year-round or seasonally and are thus most often fouled with mussels. This relatively small group of recreational boats is then a high-risk vector for zebra mussel in Switzerland. We estimated that up to 800 high-risk overland transport events take place each year (Fig. 6). Considering that we found transport events among almost all navigable water bodies in Switzerland, this number may be high enough for creating a significant propagule pressure for the spread of this and other fouling species (Lockwood et al. 2005). As we also found bryozoan statoblasts and egg clutches of benthic invertebrates in our fouling samples, we suggest that various fouling organisms are continuously transported by recreational boating between water bodies in Switzerland.

Both our survey and our field sampling campaign revealed that between 40 and $50 \%$ year-round or seasonally moored recreational boats carried mussels. Although the use of these boats is usually limited to a single water body, they are still occasionally transported over land and thus are an important distribution vector for zebra mussels. In contrast, boats kept on trailers are more often moved between different water bodies, but are rarely fouled with mussels, undoubtedly because they are used only for short periods in water (e.g. few days), which is certainly too short a period for successful mussel settlement (Kavouras and Maki 2003; Wainman et al. 1996). Johnson et al. (2001) also did not find mussel fouling on trailered boats at boat ramps. Instead, they found that zebra mussels were mainly transported overland attached to aquatic macrophytes, which were frequently entangled to such boats, equipment or trailers. In contrast, we did not find any macrophytes or other organisms on boats or boat trailers, because dense macrophyte beds are not common in Swiss navigable waters and because navigation near shore, where macrophytes are more common, is strictly regulated or even prohibited.

The most effective vector for the spread of zebra mussels may thus be boats that are kept for more than one season in water and harbor larger mussels (10-20 mm) attached to the hull. Such larger zebra mussels may be reproductive at the age of about 1 year (Ram et al. 1996). After overland transport, these mussels might not only fall off in the target lake, but also reproduce, releasing millions of gametes forming larvae and introducing a cohort of juvenile mussels into the destination water body. Our survey data showed that almost all overland transport events took place between May and September, overlapping widely with the spawning season of zebra and quagga mussels (Supplementary Material, Fig. S6). Thus we speculate that even a few transport events of fouled boats to an uninvaded lake can lead to establishment of a new mussel population, assuming that the environmental conditions are suitable for survival and reproduction.

Our data on distribution and frequency of transport events suggests that the resulting propagule pressure in the water bodies varies considerably and may not be correlated to geographic distance among them but depend more on the size and popularity of the water bodies serving as recreational targets. The main boat transportation routes are between the large lakes such as Lake Constance, Lake Geneva, Lake Zürich and Lake Lucerne (Fig. 4). In general, the larger productive lakes located in rather densely populated areas (Liechti and Jakob 1992) also have the highest mussel densities and highest fouling rates on boats. These same lakes also harbor highest numbers of recreational boats and serve as the starting point for many boat transport events of both on land-stored and moored boats (Fig. 5). Similarly Bossenbroek et al. (2007) showed in a gravity model, that the transportation rate of zebra mussels through recreational boating was high among already invaded lakes in the US, but the probability of a transport to uninvaded lakes was low. 
Their model was in accordance with the observation, that the range expansion of zebra mussels had slowed down in recent years (Johnson et al. 2006). We observed a similar effect on the range expansion of zebra mussels in Switzerland. Unfortunately, the data on zebra mussel invasion to Switzerland are not detailed enough to analyze how, with hindsight, the pattern of present spread of zebra mussels matches the boat transportation pattern we discovered. But at least we can predict that these lakes are likely to serve as important hubs for the further spread of zebra mussels and other fouling species. In more recent invasions of lakes and rivers in Switzerland, for example by $D$. villosus (Bacela-Spychalska et al. 2013; Hesselschwerdt et al. 2008), one surprising pattern has been that the invasive range extended rapidly including considerable jumps over longer overland distances between water bodies. Such a pattern has been related to over land transport of recreational boats (Bacela-Spychalska et al. 2013) and is compatible with the transportation frequencies and routes of recreational boats shown by this study.

An interesting point emerging from our questionnaire is that some alpine lakes at higher altitude serve as a target for boat transport (Fig. 5), but seem to have remained uninvaded by zebra mussels (To date, zebra mussels have not been found above 1300 m.a.s.l., Fig. 1). As the frequency of transport events is low, from these data it is not clear whether the propagule pressure in these lakes was too low for the establishment of zebra mussel populations or whether the environmental niche did not allow the establishment of a new population (Rouget and Richardson 2003; Simberloff 2009; Von Holle and Simberloff 2005). We suspect the latter. Duration of the warm water period $\left(>12{ }^{\circ} \mathrm{C}\right)$ in the summer is hypothesized to be the limiting boundary for the spread of zebra mussels (Borcherding 1991). In higher elevation warm water period in the summer is short and may constrain the reproductive cycle of the mussels.

In the end the question of how to manage the propagule pressure of fouling species in vulnerable water bodies remains. We consider that in the lower elevation lakes where transport events occur at higher frequency the propagule pressure can be taken as continuous in the sense that the introductions are frequent enough that the location will eventually be colonized. Regulation of boat movements is relatively lax in Switzerland. We suggest that well-targeted measures against unintended transport of mussels by recreational boats, which have already been tested intensively in the US (see e.g. ANS-Task-Force 2015), could significantly reduce the propagule pressure of fouling species. Our data shows that it might be sufficient to focus prevention measures to the relatively small group of boats that are moored seasonally or all year-round and transported. We estimated that this group comprises roughly $6 \%$ of all registered boats in Switzerland (about 6000 boats). With measures focusing on this group, the roughly 800 transport events with a high risk of transporting mussels between water bodies could be prevented (Fig. 6). Such measures should include detailed information to the boat owners who moor their boats permanently or seasonally, opportunities for easy and effective cleaning of the boats at boat ramps and enforcement of regulations for safe boat transfer. We estimate that focusing measures on the transport of boats that are kept year-round or seasonally in water would cover about $90 \%$ of all high risk transport events. Our data illustrates that it is of prime importance to adapt management measures to the behavior of potential human-mediated vectors specific to a region or country.

We suggest that our vector data could be combined with an environmental niche model (Elith and Leathwick 2009; Kearney and Porter 2009) to evaluate the probability of establishment both as a function of transport frequency (propagule pressure) and ecological niche availability (resistance of native ecosystem, Leung and Mandrak 2007). This approach would be particularly relevant for modelling future spread of zebra mussels to higher elevation lakes, which may become vulnerable to invasion as climate change proceeds. Such models could also be used to predict spread of potential new invasions like the quagga mussel, Dreissena rostriformis bugensis. Quagga mussels have already been reported in the Rhine River and many of Dutch lakes (also densely colonizing shallow areas and harbors), and there is a clear risk that it will spread to lakes in Switzerland (Martens and Schiel 2012; Matthews et al. 2014). Quagga mussels were found to have lower rates of spread than zebra mussels on large spatial scales potentially due to differences in populations dynamics and habitat preferences (Karatayev et al. 2011). Another reason may be that quagga mussels are less resistant to desiccation than 
zebra mussels and thus the proportion of surviving quagga mussels during over land transport may be lower (Ricciardi et al. 1995). Nevertheless, quagga mussels can attach to hard surfaces such as boat hulls, and their spread to isolated lakes has been repeatedly linked to the overland transport of recreational boats (Karatayev et al. 2011; Martens and Schiel 2012; Stokstad 2007). Because quagga mussels were found to survive and reproduce better at lower temperatures (Roe and MacIsaac 1997) and under low food conditions (Baldwin et al. 2002) than zebra mussels they may also colonize the colder, oligotrophic lakes in higher elevations, which have not been colonized by zebra mussels so far. Future research should focus on collecting environmental data on the possible target lakes to parameterize environmental niche models.

\section{Concluding remarks}

Although the zebra mussel is now widely established in Swiss waters, our study provides quantitative information on a key vector of secondary spread that can be used to prevent or slow down the further spread of this species as well as of other fouling species that pose a significant invasion risk, such as bryozoa and amphipods. The quagga mussel is of particular concern as it is already found in the Rhine River and has a great potential to spread similarly throughout Swiss navigable waters (but see Bossenbroek et al. 2007). We know now, however, that a particular group of boats could play a major role as a likely vector for spreading quagga, and this knowledge permits more efficient prevention measures if swift action is taken. Specifically, any recreational boats that have been moored in mussel-invaded waters outside of the country and are then transported to Switzerland are a real risk for quagga mussel introduction. It should be possible to stop these boats at the border, quarantine and thoroughly clean them to prevent quagga mussel introduction. Moreover, from our data we can predict which lakes in the observed area are most likely to be invaded next by quagga mussels, and we may use this knowledge for future monitoring plans and measures reducing the spread of quagga mussels among Swiss lakes should they become established.
Acknowledgments We thank Prof. Ladd Johnson and three anonymous reviewers for the constructive comments on our manuscript and the Cantonal Waterways and Shipping Offices for helping us with sending our survey to a random sample of boat owners. Special thanks also go to Elisabeth Britt, Gabriela Etter, Sabrina Moerz, Jessica Lardon and Tiago Pereira for help with our field sampling campaign and to all boat owners who filled in the questionnaire. This work was financed by the Swiss Federal Office for the Environment (FOEN) and the Swiss Federal Institute for Environmental Sciences and Technology (Eawag). Data on the registered boats in Switzerland were provided by the Swiss Federal Statistical Office and data on densities of zebra mussel larvae and temperature in Lake Zürich was provided by Oliver Koester (Wasserversorgung, City of Zürich).

\section{References}

ANS-Task-Force (2015) Protect your waters. In: Aquatic Nuisance Species (ANS) Task force, U.S. Fish and Wildlife Service. http://www.protectyourwaters.net/. Accessed 21 June 2015

Bacela-Spychalska K, Grabowski M, Rewicz T et al (2013) The “killer shrimp' Dikerogammarus villosus (Crustacea, Amphipoda) invading Alpine lakes: overland transport by recreational boats and scuba-diving gear as potential entry vectors? Aquat Conserv Mar Freshw Ecosyst 23:606-618

Baldwin BS, Mayer MS, Dayton J et al (2002) Comparative growth and feeding in zebra and quagga mussels (Dreissena polymorpha and Dreissena bugensis): implications for North American lakes. Can J Fish Aquat Sci 59:680-694

Baur B, Schmidlin S (2007) Effects of invasive non-native species on the native biodiversity in the river Rhine. In: Nentwig W (ed) Biological invasions. Springer, Berlin, pp 257-273

Bij de Vaate A, Jazdzewski K, Ketelaars HAM et al (2002) Geographical patterns in range extension of Ponto-Caspian macroinvertebrate species in Europe. Can J Fish Aquat Sci 59:1159-1174

Borcherding J (1991) The annual reproductive cycle of the freshwater mussel, Dreissena polymorpha Pallas, in lakes. Oecologia 87:208-218

Bossenbroek JM, Johnson LE, Peters B et al (2007) Forecasting the expansion of zebra mussels in the United States. Conserv Biol 21:800-810

Elith J, Leathwick JR (2009) Species distribution models: ecological explanation and prediction across space and time. Annu Rev Ecol Evol Syst 40:677-697

Fagan WF (2002) Connectivity, fragmentation, and extinction risk in dendritic metapopulations. Ecology 83:3243-3249

Havel JE, Kovalenko KE, Thomaz SM et al (2015) Aquatic invasive species: challenges for the future. Hydrobiologia 750:147-170

Hesselschwerdt J, Necker J, Wantzen KM (2008) Gammarids in Lake Constance: habitat segregation between the invasive Dikerogammarus villosus and the indigenous Gammarus roeselii. Fundam Appl Limnol Arch Hydrobiol 173:177-186 
Johnson LE, Carlton JT (1996) Post-establishment spread in large-scale invasions: dispersal mechanisms of the zebra mussel Dreissena polymorpha. Ecology 77:1686-1690

Johnson LE, Ricciardi A, Carlton JT (2001) Overland dispersal of aquatic invasive species: a risk assessment of transient recreational boating. Ecol Appl 11:1789-1799

Johnson LE, Bossenbroek JM, Kraft CE (2006) Patterns and pathways in the post-establishment spread of non-indigenous aquatic species: the slowing invasion of North American inland lakes by the zebra mussel. Biol Invasions $8: 475-489$

Karatayev AY, Burlakova LE, Mastitsky SE et al (2011) Contrasting rates of spread of two congeners, Dreissena polymorpha and Dreissena rostriformis bugensis, at different spatial scales. J Shellfish Res 30:923-931

Kavouras JH, Maki JS (2003) Effects of biofilms on zebra mussel postveliger attachment to artificial surfaces. Invertebr Biol 122:138-151

Kearney M, Porter W (2009) Mechanistic niche modelling: combining physiological and spatial data to predict species' ranges. Ecol Lett 12:334-350

Kelly N, Wantola K, Weisz E et al (2013) Recreational boats as a vector of secondary spread for aquatic invasive species and native crustacean zooplankton. Biol Invasions 15:509-519

Kinzelbach R (1992) The main features of the phylogeny and dispersal of the zebra mussel (Dreissena polymorpha). In: Neumann D, Jenner HA (eds) Zebra Mussel Dreissena Polymorpha-ecology, biological monitoring and first applications in the water quality management. Gustav Fischer Verlag, Stuttgart, pp 5-17

Leung B, Mandrak NE (2007) The risk of establishment of aquatic invasive species: joining invasibility and propagule pressure. Proc R Soc B Biol Sci 274:2603-2609

Leuven REW, Velde G, Baijens I et al (2009) The river Rhine: a global highway for dispersal of aquatic invasive species. Biol Invasions 11:1989-2008

Liechti P, Jakob A (1992) Average concentrations of selected chemical parameters in surface waters. Hydrological atlas of Switzerland. Institute of Geography of the University of Berne, Bern

Lockwood JL, Cassey P, Blackburn T (2005) The role of propagule pressure in explaining species invasions. Trends Ecol Evol 20:223-228

Martens A, Schiel F-J (2012) First record of the quagga mussel Dreissena rostriformis bugensis (Andrusov) in an isolated lake in Central Europe (Bivalvia: Dreissenidae). Lauterbornia, D-86424 Dinkelscherben 75:109-111

Matthews J, Van der Velde G, Bij de Vaate A et al (2014) Rapid range expansion of the invasive quagga mussel in relation to zebra mussel presence in The Netherlands and Western Europe. Biol Invasions 16:23-42
Minchin D, Maguire C, Rosell R (2003) The zebra mussel (Dreissena polymorpha Pallas) invades Ireland: human mediated vectors and the potential for rapid intranational dispersal. Biol Environ 103B:23-30

Minchin D, Floerl O, Savini D et al (2006) Small craft and the spread of exotic species. In: Davenport J, Davenport J (eds) The ecology of transportation: managing mobility for the environment. Springer, Dordrecht, pp 99-118

Paukstis GL, Tucker JK, Bronikowski AM et al (1999) Survivorship of aerially-exposed zebra mussels (Dreissena polymorpha) under laboratory conditions. J Freshw Ecol 14:511-517

Ram JL, Fong PP, Garton DW (1996) Physiological aspects of zebra mussel reproduction: maturation, spawning and fertilization. Am Zool 36:326-338

R-Core-Team (2014) Development Core Team, R: a language and environment for statistical computing. R Foundation for Statistical Computing, Vienna. ISBN 3-900051-07-0

Ricciardi A, Serrouya R, Whoriskey FG (1995) Aerial exposure tolerance of zebra and quagga mussels (Bivalvia, Dreissenidae)_implications for overland dispersal. Can J Fish Aquat Sci 52:470-477

Roe SL, MacIsaac HJ (1997) Deepwater population structure and reproductive state of quagga mussels (Dreissena bugensis) in Lake Erie. Can J Fish Aquat Sci 54:2428-2433

Rothlisberger JD, Chadderton WL, McNulty J et al (2010) Aquatic invasive species transport via trailered boats: what is being moved, who is moving it, and what can be done. Fisheries 35:121-132

Rouget M, Richardson DM (2003) Inferring process from pattern in plant invasions: a semimechanistic model incorporating propagule pressure and environmental factors. Am Nat 162:713-724

Sala OE, Chapin FS, Armesto JJ et al (2000) Global biodiversity scenarios for the year 2100. Science 287:1770-1774

Simberloff D (2009) The role of propagule pressure in biological invasions. Annu Rev Ecol Evol Syst 40:81-102

Stokstad E (2007) Feared quagga mussel turns up in western United States. Science 315:453

Swiss Federal Statistical Office (2014) Schiffsbestände nach Bootskategorien und Kantonen. Ohne eidgenössische Konzession. In: Swiss Federal Statistical Office (FSO). http://www.bfs.admin.ch/bfs/portal/de/index/themen/11/ 03/blank/02/02.html

Von Holle B, Simberloff D (2005) Ecological resistance to biological invasion overwhelmed by propagule pressure. Ecology 86:3212-3218

Wainman BC, Hincks SS, Kaushik NK et al (1996) Biofilm and substrate preference in the dreissenid larvae of Lake Erie. Can J Fish Aquat Sci 53:134-140 